\section{Development of Genic Male-sterile Watermelon Lines with Delayed-green Seedling Marker}

\author{
X.P. Zhang, B.B. Rhodes, and W.V. Baird \\ Department of Horticulture, Clemson University, Clemson, SC 29634 \\ H.T. Skorupska \\ Department of Agronomy and Department of Biological Sciences, Clemson \\ University, Clemson, SC 29634
}

\section{W.C. Bridges \\ Department of Experimental Statistics, Clemson University, Clemson, SC 29634}

Additional index words. backcross, breeding, Citrullus lanatus, germplasm, hybrid, pedigree, seed production

\begin{abstract}
Hybrid seed production can be facilitated by using male sterility coupled with a seedling marker. This research was initiated to combine the $m s$ male sterility and $d g$ delayed-green seedling marker into watermelon [Citrullus lanatus (Thunb.) Matsum. \& Nakai] lines. Male-sterile plants of the male-sterile line G17AB were crossed with plants of delayed-green breeding line Pale90, which has yellow cotyledons and pale-green, newly developed, true leaves. The double-recessive recombinants, male sterile and delayed green, from the $F_{2}$ population were backcrossed to the male-fertile plants of G17AB. The pedigree method was used for selection in the progenies. The segregation ratios obtained from $F_{2}$ and $B_{1} F_{2}$ populations suggest that the male-sterile and delayed-green traits are inherited independently and that delayed green is inherited as a single recessive nuclear gene. Two male-sterile watermelon lines with delayed-green seedling marker have been developed. These lines will provide a convenient way to introduce male sterility and the delayed-green seedling marker into various genetic backgrounds. These two lines can be used for testing the efficiency of a new, hybrid, watermelon, seed production system.
\end{abstract}

Hybrid cultivars are the mainstream of commercial watermelon production. Compared with open-pollinated cultivars, hybrids increase yield, produce more uniform fruit, and have better quality and enhanced performance in diverse environments. Hybrid seeds usually are produced by hand-pollination. Female flowers of the seed parent and male flowers of the pollen parent need to be covered to prevent undesirable cross or selfpollination. The seeds produced also need to be tested for hybrid purity because plants resulting from self-pollination will produce undesirable fruit. In most cases, if not all, hybrid seed testing must be performed in the field over 2 to 3 months. The extra time and labor involved in pollination and seed testing make diploid hybrid seeds $\approx 10$ times and triploid hybrid seeds $\approx 100$ times more expensive than open-pollinated seeds.

Received for publication 17 Jan. 1995. Accepted for publication 19 Oct. 1995. This article is technical contribution no. 4039 of the South Carolina Agricultural Expt. Station, Clemson Univ., Clemson. This work was supported in part by the U.S. Dept. of Agriculture, Office of International Cooperation and Development. The cost of publishing this paper was defrayed in part by the payment of page charges. Under postal regulations, this paper therefore must be hereby marked advertisement solely to indicate this fact.
Male sterility can be used to reduce the cost of hybrid seed production (Driscoll, 1986; Kaul, 1988; Rao et al., 1990). The first malesterile watermelon mutant was identified in an $\mathrm{X}_{2}$ generation of 'Sugar Baby' irradiated by gamma rays (Watts, 1962). The mutation is inherited as a single recessive nuclear gene $(\mathrm{gms})$, and sterility is always associated with glabrousness, suggesting a pleiotropic effect, or tight linkage of the two loci. The possibility of identifying male-sterile plants at the seedling stage was attractive to breeders and seed producers (Love et al., 1986). Unfortunately, expression of the gms gene not only results in male sterility but also considerably reduces female fertility. Although female fertility in the diploid can be improved by continuous selection (Watts, 1967), the tetraploid of this mutant is virtually female-sterile. In addition, expression of the gms is not stable. The sterile plants occasionally produce fertile male flowers late in the season (Watts, 1962, 1967).

In 1982, a spontaneous, male-sterile watermelon mutation was found in China and was developed into the male-sterile line G17AB (Xia et al., 1988; Zhang and Wang, 1990). This mutation is inherited as a single recessive nuclear gene $(\mathrm{ms})$. Plant morphology and female fertility of $m s$ male-sterile plants are normal and identical to those of wild-type, male-fertile plants. The $m s$ gene is expressed consistently under various environments and in diverse genetic backgrounds (Zhang et al., 1994). This mutation has been introduced into many breeding lines and is being used for hybrid seed production in China (Zhang and Rhodes, 1992). When genic male-sterility is used for hybrid seed production, male-fertile plants in the male-sterile line have to be removed before anthesis to ensure that all seeds harvested from male-sterile plants are hybrids. Because male-fertile plants may escape detection, field testing of hybrid purity is still required. Introducing a seedling marker into the $m s$ male-sterile line will enable seed producers to test their seeds at an early stage of development in the laboratory or the greenhouse. Also, hand-pollination can be eliminated in backcross breeding (most commonly used to transfer the male-sterile trait to various backgrounds) by using a seedling marker (Carter et al., 1983).

A leaf color mutant, delayed green $(d g)$, has been reported previously in watermelon (Rhodes, 1986). The newly developed true leaf of this mutant appears pale green, especially at the seedling stage, but the trait is difficult to identify in later stages. We observed variation in cotyledon color in advanced inbred generations. Variants with yellow cotyledons and delayed-green true leaves were self-pollinated and selected for these traits. The newly selected line (Pale90) with

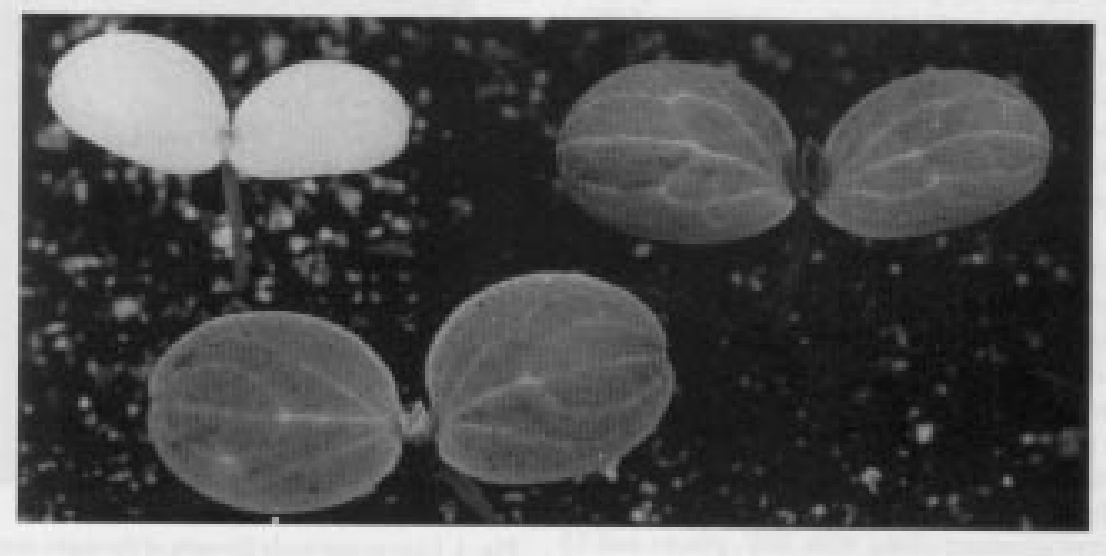

Fig. 1. Variation of cotyledon color in the original Pale population at the cotyledon stage. (top left) Variant with yellow cotyledons and delayed-green true leaves was used in this study. (top right) Normal green wild type. (bottom) Variant with green cotyledons and delayed-green true leaves. 
yellow cotyledons is easily differentiated from the wild type with green cotyledons as soon as the cotyledons emerge. Thus, this character is an ideal seedling marker for distinguishing seedlings that result from either self- or crosspollinations.

Combining $d g$ and $m s$ traits in watermelon lines should facilitate using $m s$ in watermelon hybrid seed production. At least two advantages can be expected from the system that uses male sterility and seedling marker for hybrid watermelon seed production compared with the system using male sterility only. First, hybrid purity can be tested in the laboratory or greenhouse as soon as cotyledons emerge. Seedlings with green cotyledons are from crosspollination, while seedlings with yellow cotyledons are from self-pollination. Second, offtypes in the seed parent line, resulting from cross-pollination and mechanical mixing during seed propagation, can be rogued at an early developmental stage. Linkage of an early expressed and easily scored marker gene with a male-sterile locus facilitates early removal of male-fertile plants from the female rows in a hybrid seed production program (Driscoll, 1986; Jorgensen, 1987; Kaul, 1988; Rao et al., 1990). Breeding efforts were initiated to combine the newly selected $d g$ seedling marker (yellow cotyledons and delayed-green true leaves) and the $m s$ male-sterile, female-fertile character into watermelon lines, to study inheritance of the newly selected $d g$ mutant, and to exploit any linkage between these traits in the breeding program. We report the results of genetics and breeding experiments conducted during this study.

\section{Materials and Methods}

Two breeding lines, G17AB and Pale90, were used to make crosses. Xitong Xia (Shengyang Agricultural Institute, Shengyang, Liaoning, China) kindly provided G17AB, a breeding line containing the $m s$ gene. The population of G17AB segregates 1 male-sterile plant: 1 male-fertile plant. This line always sets fruit easily in the greenhouse during the winter and in the field during the summer, and fruit are round with light green background and green stripes. Pale90, a breeding line containing the $d g$ gene, was selected for yellow cotyledons and delayed-green true leaf (Fig. 1) from previously described delayed-green stocks (Rhodes, 1986). This line produces round fruit with a dark-green rind and lightred flesh. Average fruit mass of the parental lines is $\approx 4.5 \mathrm{~kg}$.

The initial crosses between G17AB malesterile plants and delayed-green plants were made in 1990 (Fig. 2). The $\mathrm{F}_{1}$ plants were selfpollinated in the field at Edisto Research \& Education Center (EREC), Blackville, S.C., during Summer 1991. $F_{2}$ plants were grown in a greenhouse in pots during the consistently overcast winter of 1991. Because of limited space in the greenhouse, only $111 \mathrm{~F}_{2}$ plants were screened along with $30 \mathrm{~F}_{1}$ plants and 15 plants of each parent. $F_{2}$ plants were first selected for yellow cotyledon color, then malesterile $\mathrm{F}_{2}$ plants were selected and backcrossed

$m s m s D g D g \quad \downarrow^{M s M s d g d g}$

F1:<smiles>[Mg][Mg][Mg]</smiles>

F2: $\quad$ Select male-sterile delayed-green plants. Backeross with male-fertile plants of G17AB. msmsdgdg $x M \operatorname{Ms} s \mathrm{Dg} D g$<smiles>[AlH2]</smiles>

BCIF1: 1 msmsDgdg : 1 MsmsDgdg

$\downarrow$ sib-crosses

BC1F2: $\quad$ Select delayed-green plants at seedling stage. Harvest seeds from male-sterile plant pollinated using pollen from a male-fertile plant with similar or identical fruit traits.

$\downarrow$ sib-crosses

BCIF3: $\quad$ Test selected lines for delayed green, male sterility and fnuit traits.

$\downarrow$

\section{MSDG-1 MSDG-2}

Fig. 2. Pedigree of male-sterile, delayed-green watermelon lines MSDG-1 and MSDG-2.
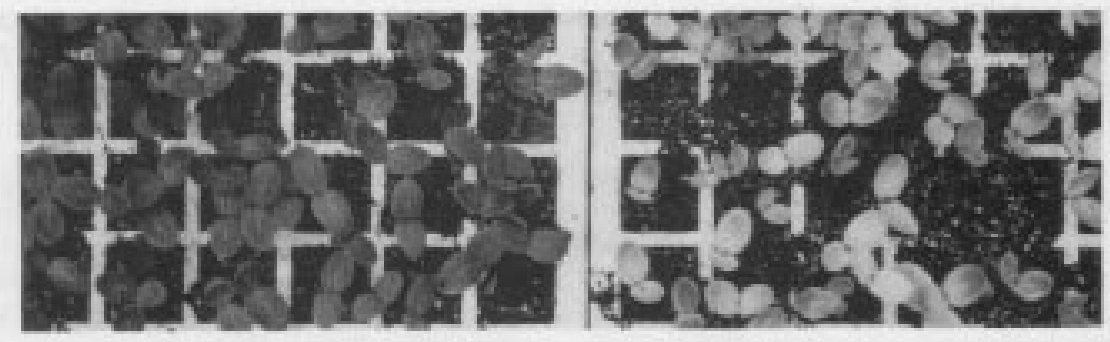

Fig. 3. Cotyledon color of the (right) male-sterile, delayed-green watermelon lines (MSDG-1) and (left) normal-green, male-sterile line $(\mathrm{G} 17 \mathrm{AB})$ at the cotyledon stage.

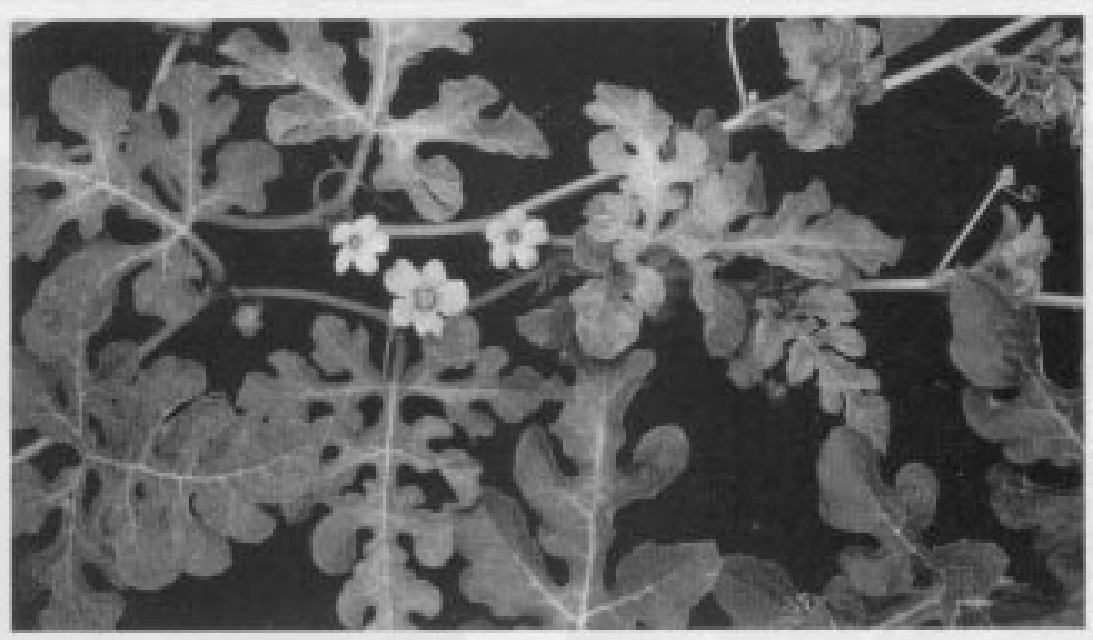

Fig. 4. Leaves and male flowers of the male-sterile, delayed-green watermelon lines (MSDG-1). The young leaves (near the flowers) are pale green and the older leaves (right and left corners) are normal green. The upper two male flowers are from the male-sterile plant and the lower male flower is from the malefertile plant. 
with male-fertile $\mathrm{G} 17 \mathrm{AB}$ plants. $\mathrm{BC}_{1} \mathrm{~F}_{1}$ plants were grown in the field at EREC and sibcrossed during Summer 1992. Seeds from a sib-crossed $\mathrm{BC}_{1} \mathrm{~F}_{1}$ plant were germinated in the greenhouse in Apr. 1993, and only $\mathrm{BC}_{1} \mathrm{~F}_{2}$ individuals with yellow cotyledons were transplanted to the field. The selected plants were scored individually for male fertility, rind and flesh color, and flesh soluble solid concentration. Male-sterile plants were sib-crossed to male-fertile plants, and only fruit from malesterile plants pollinated using pollen from a fertile plant with similar or almost identical fruit traits were selected for harvesting seeds. The selected MSDG-1, 2, and 3 lines were tested in the field at EREC during Summer 1994.

\section{Results and Discussion}

Genetics. Inheritance of the newly selected, yellow-cotyledon, delayed-green, true-leaf mutant was studied using a $\mathrm{BC}_{1} \mathrm{~F}_{2}$ population. A 426 normal green : 129 yellow cotyledon, delayed-green, true-leaf seedling segregation was obtained from 555 seedlings of $\mathrm{BC}_{1} \mathrm{~F}_{2}$ population. This ratio fits a $3: 1$ segregation $\left(\chi^{2}\right.$ $=0.9135, P=0.25$ to 0.50 ) for single recessive nuclear gene inheritance but fails to support a $13: 3$ ratio $\left(\chi^{2}=7.3550, P<0.01\right)$ for the involvement of the dominant $I-d g$ allele at the $d g$ locus. The existence of the $I-d g$ allele had been suggested to explain altered expression of $d g . I-d g$ is epistatic to $d g: d g d g I-d g I-d g$ and $d g d g I-d g i-d g$ plants are delayed green, and dgdgi-dgi-dg plants are normal (Rhodes, 1986). Therefore, in our advanced selections, the new mutant showing yellow cotyledons and delayed-green true leaves is only controlled by the $d g$ gene. Early expression (at cotyledon emergence) and simple inheritance of the gene make the new selection an excellent seedling marker line to use.

We are investigating the linkage relationship between the $m s$ locus and the available seedling marker genes in all our breeding efforts related to the $m s$ gene. In the genetic testing of the $m s$ and the $d g$ traits, cotyledons and true leaf color of $F_{1}$ seedlings were normal, as were those of G17AB, whereas seedlings of Pale 90 showed typical yellow cotyledons and pale-green, newly developed, true leaves. Twenty-three delayed-green seedlings (dgdgMsMs, dgdgMsms, or dgdgmsms) and, later, seven delayed-green, male-sterile seedlings (dgdgmsms) from the 23 delayed-green seedlings were derived from the original 111 $\mathrm{F}_{2}$ individuals. The resulting segregation (88:16:7) fits the expected ratio of 12:3:1 for normal-green male-sterile/fertile to delayedgreen male-fertile to delayed-green malesterile $\left(\chi^{2}=1.3844, P=0.50\right.$ to 0.75$)$. This result suggests that $m s$ and $d g$ loci are inherited independently and confirms that the newly selected $d g$ mutant is inherited as a single recessive nuclear gene. Also, the $\mathrm{BC}_{1} \mathrm{~F}_{2}$ segregated 47 delayed-green, male-sterile : 50 delayed-green, male-fertile, and this ratio fits the expected $1: 1\left(\chi^{2}=0.0926, P=0.75\right.$ to $0.90)$. Thus, the $m s$ and $d g$ loci are inherited independently.

HortScience, Vol. 31(1), February 1996
Breeding. Breeding lines with yellowcotyledon (Fig. 3), delayed-green, true leaves; male sterility (Fig. 4); and improved fruit quality and rind character (Fig. 5) have been developed by the pedigree method with a single backcross. Three lines were tested in

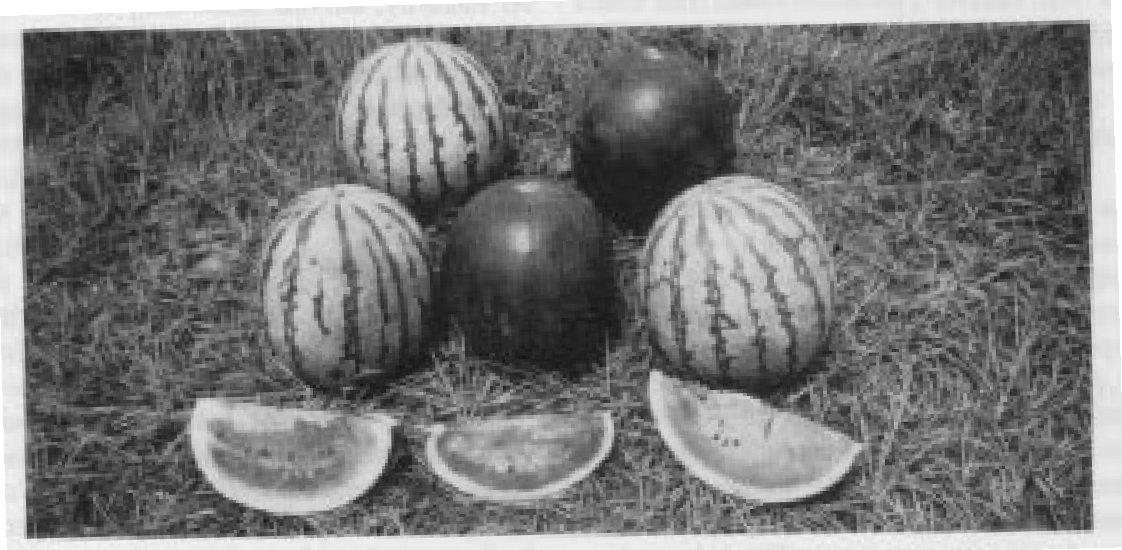

Fig. 5. Fruit of the parental lines (top left ) G17AB and (top right) Pale 90 and the male-sterile, delayedgreen watermelon lines (from left to right) MSDG-1, MSDG-2, and MSDG-3.

\section{Isolation Plots}
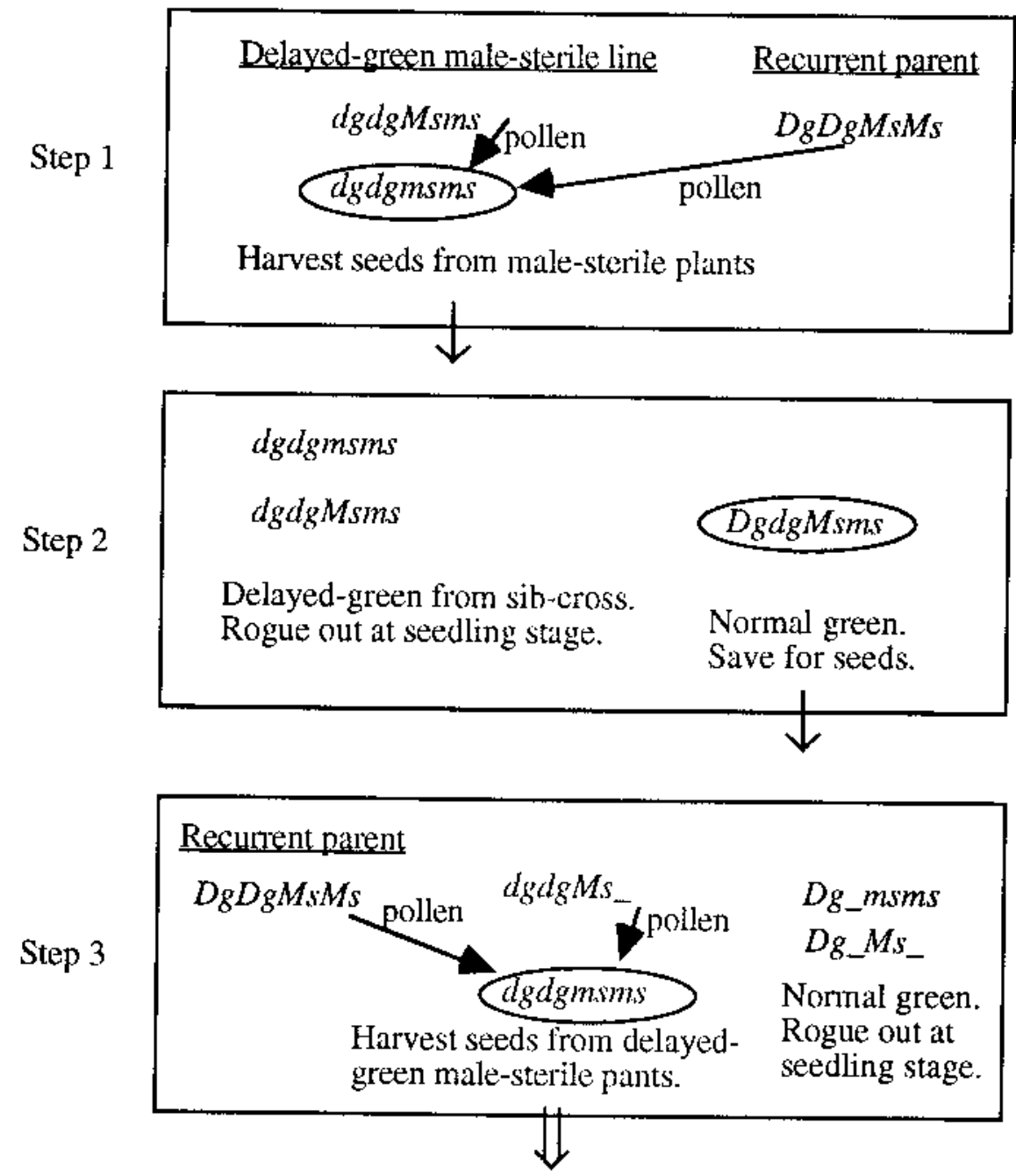

Go to step 2

Fig. 6. Procedures for introducing $m s$ and $d g$ genes from the delayed-green, male-sterile line into different genetic backgrounds without hand-pollination. 
line MSDG-1. Besides the traits of delayed green, male sterility, good fruit set ability, and bright red flesh, the new breeding lines can be distinguished by fruit appearance. MSDG-1 produces round fruit with a light-green background and dark-green stripes, similar to G17AB. MSDG-2 produces round fruit with a dark-green rind, similar to that of 'Sugar Baby'. Average fruit mass of MSDG-1 and MSDG-2 is $\approx 5 \mathrm{~kg}$. MSDG-3 still segregates for fruit color and has been discarded.

Selection of $\mathrm{F}_{2}$ progeny during winter in the greenhouse, where environmental control was poor, may have selected for stability in improved fruit set for the advanced generations. Backcrossing of double recessive (delayed-green, male-sterile) recombinants of the $\mathrm{F}_{2}$ population to male-fertile heterozygotes of male-sterile G17AB enhanced fruit quality of the progeny toward the more agronomically desirable parent (G17AB). Backcrossing also resulted in 1 sterile : 1 fertile segregation ratio in subsequent generations. The 1:1 segregation ratio simplified the selection procedure in subsequent progenies.

The two breeding lines, MSDG-1 and MSDG2, will provide valuable germplasm for introducing the $m s$ male sterility and $d g$ delayed green into various genetic backgrounds using backcrossing without labor-intensive manual cross- and self-pollinations (Carter et al., 1983). The $m s$ and $d g$ genes can be intro- duced from lines developed in this study into various genetic backgrounds by repeating steps shown in Fig. 6: 1) Plant delayed-green, malesterile plants together with male-fertile plants of the recurrent parent, which has the gene dominant to the delayed-green seedling marker. At maturity, harvest seeds only from malesterile plants. 2) Plant the seeds (from step one) in an isolation plot and rogue out the delayed-green plants at the seedling stage, which are from sib-crossing. Harvest seeds from the remaining plants at maturity. 3) Plant the seeds from step two, and rogue out the plants possessing the dominant seedling marker, ideally before transplanting to the field or even in the field before fruit set. Plant only the plants showing yellow cotyledons and delayed-green true leaves together with the recurrent parent. At maturity, harvest seed only from male-sterile plants. These procedures do not require hand-pollination and can be repeated easily until the desired number of backcrosses have been achieved.

\section{Literature Cited}

Carter, T.E., Jr., J.W. Burton, and M.F. Young. 1983. An efficient method for transferring genetic male sterility to soybean lines. Crop Sci. 23:387-388.

Driscoll, C.J. 1986. Nuclear male sterility system in seed production of hybrid varieties. CRC Critical Rev. Plant Sci. 3:227-256.
Jorgensen, R.A. 1987. A hybrid seed production method based on synthesis of novel linkages between marker and male-sterile genes. Crop Sci. 27:806-810.

Kaul, M.L.H. 1988. Male sterility in higher plants. Monogr. Theor. Appl. Genet. 10. SpringerVerlag, New York.

Love, S.L., B.B. Rhodes, and P.E. Nugent. 1986. Controlled pollination transfer of a nuclear malesterility gene from a diploid to a tetraploid watermelon line. Euphytica 35:633-638.

Rao, M.K., K.U. Devi, and A. Arundhati. 1990. Application of genic male sterility in plant breeding. Plant Breeding 105:1-25.

Rhodes, B.B. 1986. Genes affecting foliage color in watermelon. J. Hered. 77:134-135.

Watts, V.M. 1962. A marked male-sterile mutant in watermelon. Proc. Amer. Soc. Hort. Sci. 81:498505.

Watts, V.M. 1967. Development of disease resistance and seed production in watermelon stocks carrying $m s_{g}$ gene. Proc. Amer. Soc. Hort. Sci. 91:579-580.

Xia, X., Y. Liu, W. Liu, and A. Chen. 1988. Selection of watermelon (Citrullus vulgaris) malesterile line G17AB. J. Shengyang Agr. Univ. 19:9-13.

Zhang, X.P. and B.B. Rhodes. 1992. Watermelon variety improvement in China. Cucurbit Genet. Coop. Rpt. 15:76-79.

Zhang, X.P., H.T. Skorupska. and B.B. Rhodes. 1994. Cytological expression of the male-sterile ms mutant in watermelon. J. Hered. 85:279-285.

Zhang, X.P. and M. Wang. 1990. A genetic malesterile $(m s)$ watermelon from China. Cucurbit Genet. Coop. Rpt. 13:45. 